\title{
Endoscopic and surgical management of intrabiliary rupture of hydatid liver cyst
}

\author{
SEbAstian LEONG, MB,BS, MMED, DIP, VEN, YOUNG-IN KIM, MD, FRCPC, ROBIN GRAY, MD, FRCPC, \\ PAUL KORTAN, MD, FRCPC, GREGORY HABER, MD, FRCPC
}

S LEONG, Y-I KIM, R GRAY, P KORTAN, G HABER. Endoscopic and surgical management of intrabiliary rupture of hydatid liver cyst. Can J Gastroenterol $1992 ; 6(3): 135-139$. A man with hydatid disease complicated by intraabdominal cyst rupture 15 years earlier, presented with cholestatic jaundice. There was intrabiliary rupture of a hydatid liver cyst on endoscopic retrograde cholangiography. Sphincterotomy was performed to allow clearance of hydatid material obstructing the bile ducts and insertion of a nasobiliary catheter for irrigation and drainage. Definitive surgery was performed. While endoscopic management is gaining recognition for relieving biliary obstruction in hydatid cystobiliary rupture, surgery is still required for patients who continue to pass hydatid debris obstructing the biliary tree and increasing the risk of cholangitis.

Key Words: Bile duct, Endoscopic retrograde cholangiography, Hydatid cyst, Sphincterotomy

\section{Traitement endoscopique et chirurgical d'un kyste hydatique du foie rompu dans les voies biliaires}

RÉSUMÉ: Un homme atteint d'une maladie hydatique compliquée d'un kyste intra-abdominal rompu 15 ans auparavant se présente avec une jaunisse cholostatique. À la cholangiographie endoscopique rétrograde, on a pu observer la présence d'un kyste hydatique du foie rompu dans les voies biliaires. Une sphinctérectomie a été pratiquée afin de permettre l'élimination des tissus hydatiques qui obstruaient les voies biliaires et l'insertion d'un cathéter nasobiliaire pour l'irrigation et le drainage. Le tout a été suivi d'une chirurgie définitive. Bien que l'endoscopie soit de plus en plus employée dans le traitenent de l'obstruction biliaire causée par la présence d'un kyste hydatique du foie rompu, la chirurgie est toujours nécessaire chez les patients qui continuent à éliminer des débris hydatiques qui obstruent l'arbre biliaire et qui présentent un risque accru à l'égard de la cholangite.

The Wellesley Hospital, Division of Gastroenterology and Department of Radiology, University of Toronto, Toronto, Ontario

Correspondence and reprints: Dr Gregory Haber, Division of Gastroenterology, Endoscopy Unit, Room 361, The Wellesley Hospital, 160 Wellesley Street East, Toronto, Ontario M4Y IJ3. Telephone (416) 968-1063, Fax (416) 968-7696

Received for publication February 14, 1992. Accepted April 27, 1992
$\mathrm{H}$ YDATID DISEASE IS OFTEN ASYMPtomatic until complications occur and this uncommon entity may be overlooked in an emergency situation when a previously healthy patient presents for the first time. Hydatid cyst of the liver is the most common site and it produces symptoms when the cyst becomes infected, compresses or ruptures into adjacent structures or grows to an enormous size (1). A case illustrating the two main complications of hydatid disease $(1,2)$ - rupture of a hydatid liver cyst into the peritoneal cavity and, many years later, another rupture into the biliary tree - is presented. Both conditions may be life threatening and prompt management is vital for a successful outcome.

\section{CASE REPORT}

A 37-year-old man of Italian descent presented with jaundice associated with abdominal discomfort for two days. He had emigrated to Canada at 12 years of age. During his childhood he lived with his parents who were farmers, tending cattle, sheep, pigs and dogs.

At 22 years, he experienced severe abdominal pain after being hit by a ball in the abdomen. Emergency laparotomy revealed a ruptured hydatid cyst in the liver. Partial left hepatic lobectomy was performed and he made an uneventful recovery. 


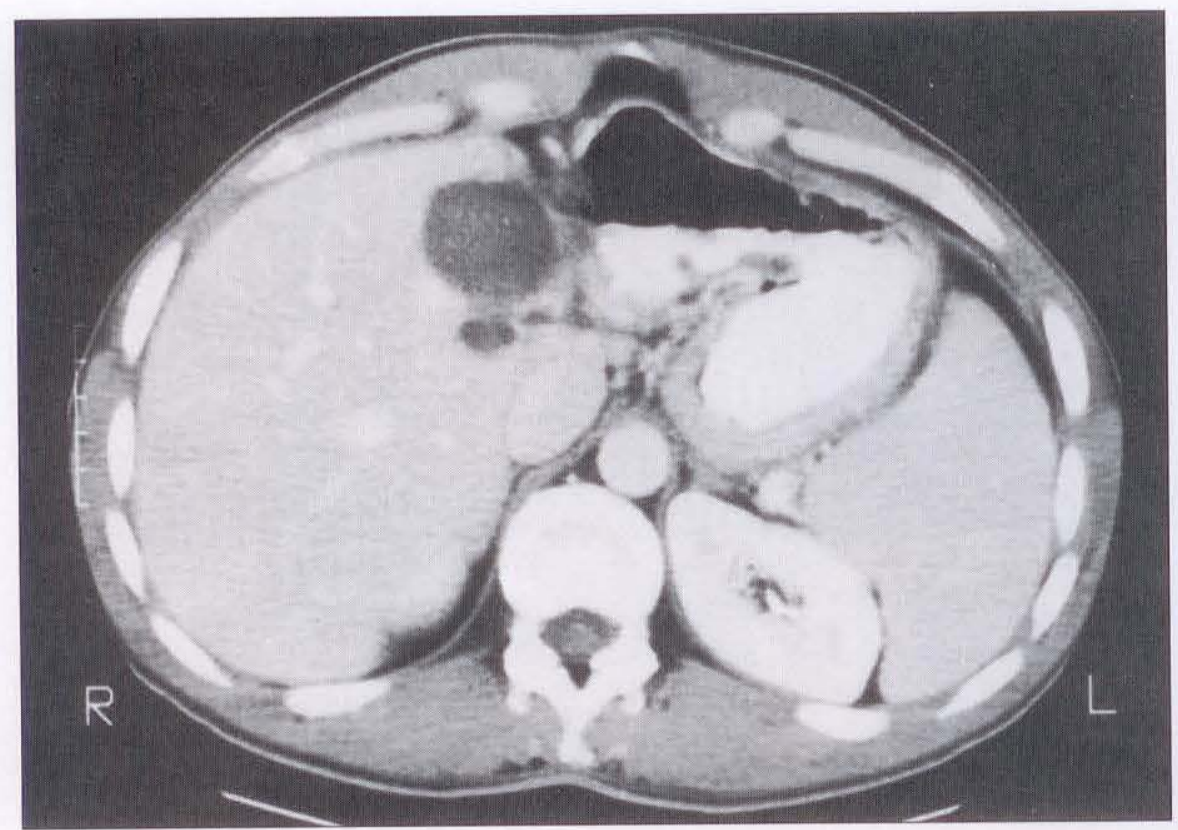

Figure 1) Computed tomography scan of abdomen showing two hydatid cysts in liver

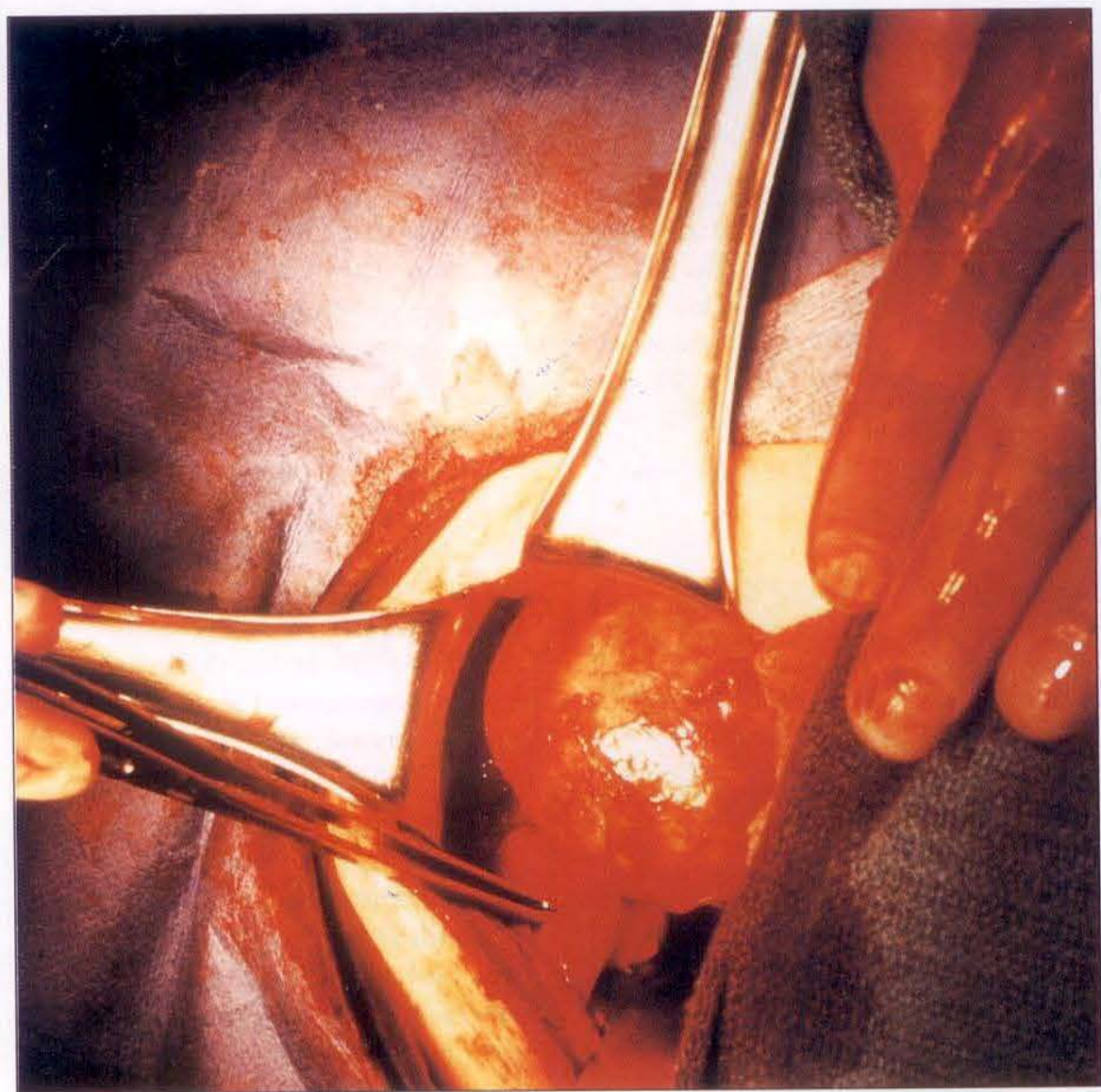

Figure 2) Cholangiogram showing filling defect due to hydatid membranes in the left hepatic duct and common bile duct

At 32 years, an ultrasound and computed tomograpy scan of the abdomen showed two small liver cysts (Figure 1) at a pre-employment check-up. No treatment was given as they were thought to be dead cysts.

At 36 years, the patient presented with lower abdominal pain. Imaging with ultrasound revealed a new pelvic cyst. He underwent a second laparotomy. The cyst was adherent to the bladder wall anteriorly, the rectum posteriorly and laterally to the pelvic wall. It was dissected intact and removed. It measured $5 \mathrm{~cm}$ in diameter and on sectioning, multiple daughter cysts were seen. With the exception of the previously noted liver cysts, no other lesions were found.

At 37 years, the patient presented with jaundice associated with upper abdominal discomfort. On abdominal examination, upper and lower midline surgical scars and a tender, enlarged liver were noted. The liver function tests were consistent with cholestatic jaundice and coagulation profile was normal. Ultrasound of the abdomen revealed a distended gall bladder and a cystic lesion in the remnant left lobe, measuring 3.9 by $4.5 \mathrm{~cm}$. The common bile duct was dilated to $1.6 \mathrm{~cm}$. The intrahepatic ducts were also dilated. Endoscopic retrograde cholangiography showed a dilated biliary tree with a cystic dilation in a branch of the left hepatic duct containing hydatid material (Figure 2). Endoscopic sphincterotomy was performed and yellowish gelatinous membranes were seen extruding from the ampullary orifice. A Dormia basket was passed to evacuate hydatid debris from the bile ducts. There was dramatic recovery with relief of biliary obstruction.

Two weeks later the jaundice recurred, associated with fever and chills, suggesting cholangitis due to biliary obstruction from continuing discharge of daughter cysts. At urgent endoscopic retrograde cholangiography, yellowish jelly-like hydatid material and pus were seen protruding out of the ampulla of Vater (Figure 3). There was hydatid debris in the dilated common bile duct and left hepatic radical, which was communicating with the cystic cavity (Figure 4). After evacuation of the debris with a basket, a nasobiliary catheter was inserted into the cyst cavity to improve drainage and allow irrigation with saline. The biliary fluid and sediments did not contain any hooklets or protoscolices on microscopy. Hence there was no evidence for 


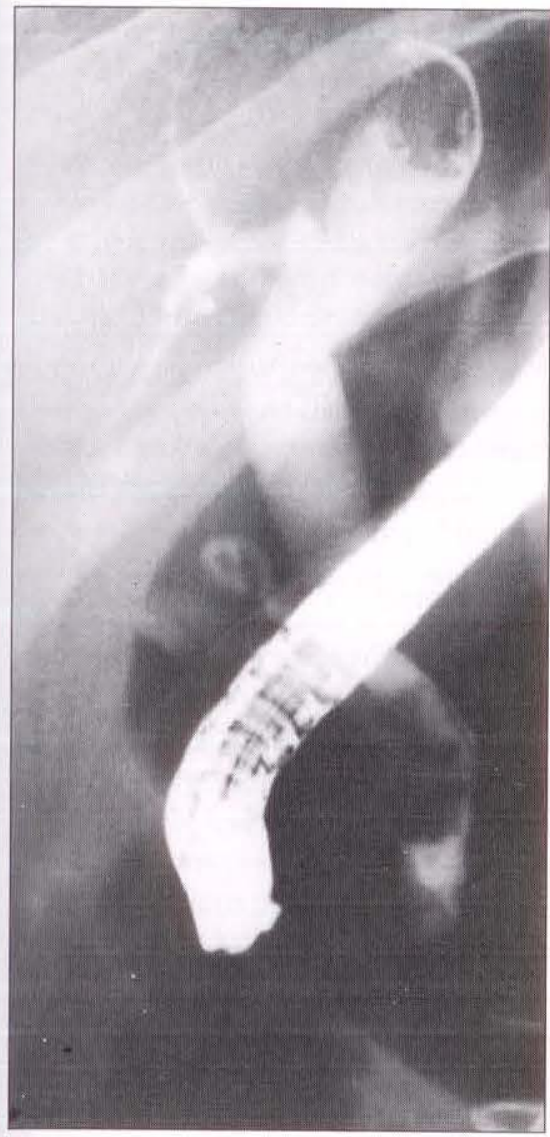

Figure 3) Hydatid membrane protruding out of opening of ampulla of Vater

viability of the parasites and medical therapy with mebendazole was not given. A repeat ultrasound of the abdomen showed a cystic cavity communicating with the left main hepatic duct which was dilated to $8 \mathrm{~mm}$.

Although the fever and jaundice subsided with a repeat clearance of the bile ducts, surgical treatment was elected to eradicate the disease. Resection of the liver containing the cyst was performed together with cholecystectomy and insertion of a $\mathrm{T}$-tube to allow intra- and postoperative cholangiography. Recovery was uneventful and nine months later the patient was asymptomatic and had returned to work without evidence of residual disease on abdominal ultrasound examination.

\section{DISCUSSION}

Hydatid disease is a parasitic infection most commonly caused by the cestode Echinococcus granulosus. Very rarely it is due to Echinococcus multi-

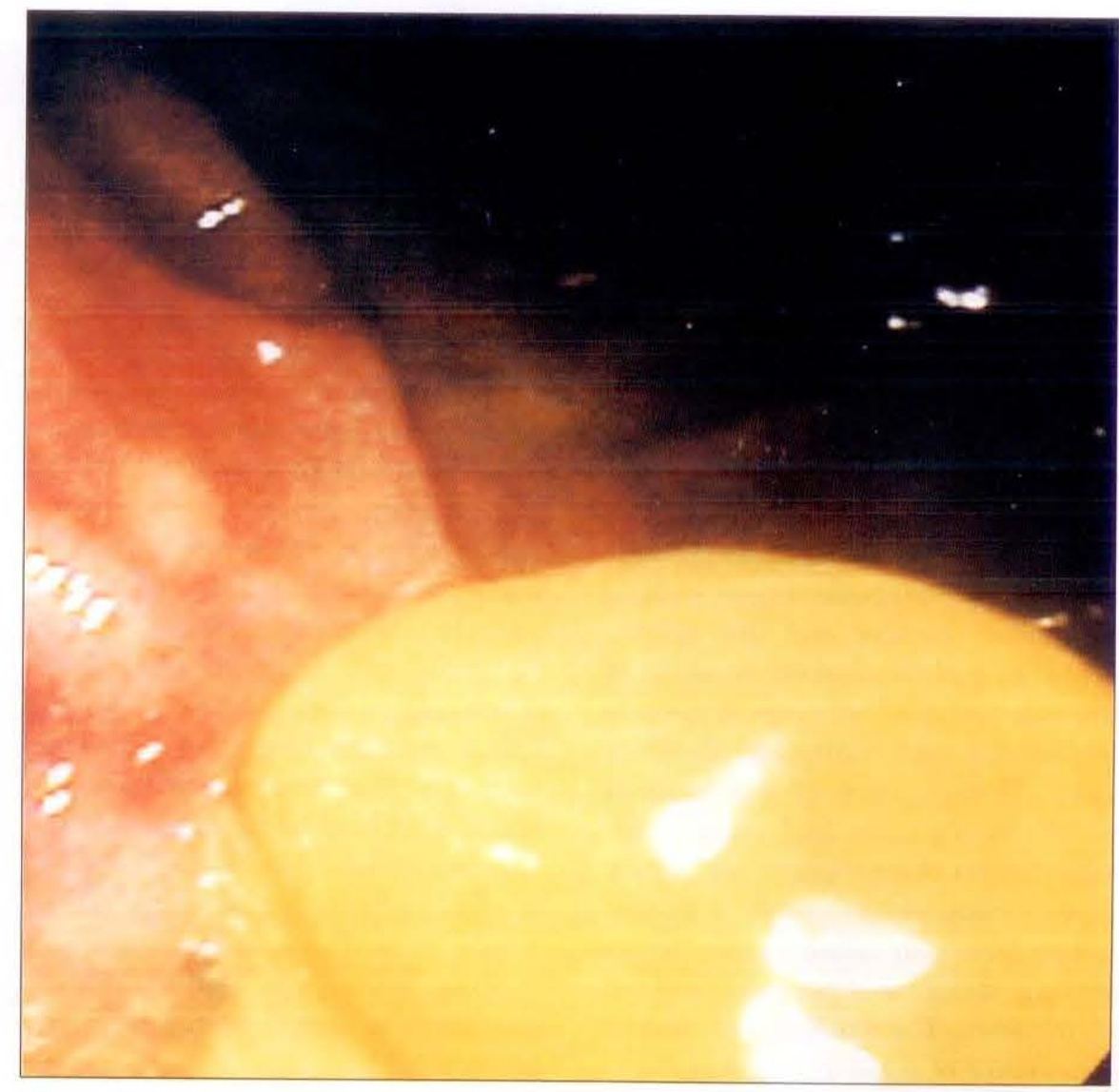

Figure 4) Cholangiogram showing metal basket in cyst cavity communicating with left hepatic duct

locularis (3). Humans, sheep and cattle are intermediate hosts and the dog is the common definitive host (1). Hydatid disease is endemic in sheep-rearing countries and it is likely that the present patient acquired the infection during his childhood in Italy from handling dogs or eating vegetables contaminated with the ova of the parasite.

With increasing immigration, human echinococcosis may be on the rise in North America since the infection is acquired in the native country during childhood. In Canada it is more common in people of Greek and Italian descent (4).

Rupture of an echinococcal cyst was the first indication of hydatid disease in this patient. Lewall et al (5) described three types of rupture: contained, communicating and direct, the last being most serious because spilling of cyst contents into the peritoneal cavity may cause allergic and infective sequelae. It is thought that patients with direct rupture should receive anthelminthic drugs to prevent peritoneal hydatidosis (6). The rupture is communicating when cyst contents escape via biliary radicles leading to obstruction of the biliary tree and cholangitis as in the presented patient. There has been no evidence that transbiliary dispersion of scolices leads to dissemination of echinococcal disease.

Cyst rupture may be due to external trauma (direct rupture) as in the initial presentation of this case, or degeneration of the parasitic membranes (communicating rupture) resulting in the release of hydatid daughter cysts and debris into the common bile duct. Hydatid cyst rupture into the biliary tree is a serious complication occurring in 5 to $15 \%$ of patients with hepatic involvement $(7,8)$. Diagnosis was made only at laparotomy until sonography became available (7-9). Sonographic visualization of ruptured cyst material into the biliary tree and communication between a cyst and the biliary tract indicate intrabiliary rupture of a 
hepatic hydatid cyst (10-12). Together with computerized axial tomography, which can demonstrate the cyst-bile duct communication sometimes difficult to visualize with ultrasound, the diagnostic accuracy can reach $96 \%$ for intrabiliary hydatid cyst rupture $(13,14)$.

Cottone et al (15) first reported the use of endoscopic retrograde cholangiography in the diagnosis of hepatic hydatid cyst rupture into the biliary tree. The endoscopic picture of yellowish gelatinous membranes protruding out of the ampulla suggest hydatid cystobiliary rupture and this is confirmed by pathological examination of the infected bile which will contain fragmented membranes and daughter cysts. The presence of pus suggests secondary infection and requires administration of appropriate antibiotics. The cholangiogram shows a dilated biliary tree with filling defects representing daughter cysts and hydatid membranes. The leaf-like radiological appearance of these membranes sometimes changes in shape on serial cholangiogram and it differentiates hydatid material from choledocholithiasis $(16,17)$. Entry of contrast into a cystic space points to a communicating type of rupture. Other radiological fea-

\section{REFERENCES}

1. Sherlock S. Diseases of the Liver and Biliary System, 8th edn. Oxford: Blackwell Scientific Publications, 1989:568-75.

2. Al-Hashami HM. Intrabiliary rupture of hydatid cysts of the liver. Br J Surg 1971;58:228-32.

3. Rausch RL, Nelson GS. A review of the genus Echinococcus. Ann Trop Med Parasitol 1963;57:127-31.

4. Langer JC, Rose DB, Keystone JS. Diagnosis and management of hydatid disease of the liver. Ann Surg 1984;199:412-7.

5. Lewall DB, McCorkell SJ. Rupture of Echinococcal cysts: Diagnosis, classification, and clinical implications. Am J Roentgenol 1986;146:391-4.

6. Pappalardo G, Reggio D, Frattaroli FM, et al. Combined medical and surgical therapy: A new approach to abdominal hydatidosis. Ital J Surg Sci 1987:17:335-9.

7. Macris G], Galanis NN. Rupture of tures include extrinsic compression of the biliary tract by a hepatic cyst, complete obstruction of extrahepatic bile ducts and biliary fistula (18). Percutaneous transhepatic cholangiography has been used to demonstrate the rupture of a cyst into the biliary tree $(19,20)$. However, there is the risk of peritoneal seeding or anaphylaxis athough diagnostic and therapeutic percutaneous aspiration of an hepatic hydatid cyst has also been described (21).

Before the advent of therapeutic endoscopy, surgery was the only effective mode of treatment for hydatid disease (15). When the hydatid cyst can be completely removed, surgical excision, partial hepatectomy or hepatic lobectomy is performed (4). In addition, cysts that have ruptured into the biliary tract must be treated as infected and the common bile duct must be explored and drained with a large calibre T-tube which would also allow a cholangiogram to be done to ensure common bile duct clearance before its removal (22).

Decompression of the biliary tree by endoscopic sphincterotomy was first reported in 1986 by Shemesh et al (23). Evacuation of hydatid debris from the obstructed biliary tree was safe and effective in preventing sepsis (23-25).

Echinococcus cyst of the liver into the biliary duct. Ann Surg 1966;32:36-44.

8. Al-Hashimi HM. Intrabiliary rupture of hydatid cyst of the liver. $\mathrm{Br} J$ Surg 1971;58:228-32.

9. Harris JD. Rupture of hydatid cyst into the biliary tract. Br J Surg 1965;52:210-2.

10. Camunez F, Simo G, Robledo R, et al. Ultrasound diagnosis of ruptured hydatid cyst of the liver with biliary obstruction. Gastrointest Radiol 1986;11:330-3.

11. Subramanyam BR, Balthazar EJ, Naidich DP. Ruptured hydatid cyst with biliary obstruction: Diagnosis by sonography and computed tomography. Gastrointest Radiol 1983;8:341-3.

12. Marti-Bonmati L, Menor F, Ballesta A. Hydatid cyst of the liver: Rupture into the biliary tree. Am J Roentgenol 1988;150:1051-3.

13. Munzer D. Evaluation of computerized axial tomography in the diagnosis of hepatic hydatid disease. J Hepatol 1982;2:114-7.
Patients with good clearance of the bile ducts avoided surgery $(26,27)$. In postoperative patients, the cause of jaundice was quickly found and endoscopic sphincterotomy with insertion of a nasobiliary catheter for irrigation replaced surgery in some patients (26). Scolicidal agents such as hypertonic saline can be used to irrigate and kill any viable parasites via the nasobiliary drain (27). This was not used in the present patient as the pathologist found no viable parasites. However, frequent irrigation via a nasobiliary catheter helps to clear the bile ducts of debris and this might have prevented a recurrence of cholangitis after the first endoscopic retrograde cholangiography and endoscopic sphincterotomy. More likely, it is the continued discharge of daughter cysts that prevents bile drainage. Other possible causes include incomplete extraction of common bile duct debris and inadequate sphincterotomy.

While endoscopic treatment of intrabiliary rupture of hydatid cyst may temporarily relieve biliary obstruction, surgery should be considered if there is persistent discharge of hydatid debris obstructing the bile ducts. This will prevent cholangitis and eradicate hydatid disease.

14. Marti-Bonmati L, Serrano FM. Complications of hepatic hydatid cysts: Ultrasound, computed tomography and magnetic resonance diagnosis. Gastrointest Radiol 1990;15:119-25.

15. Cottone M, Amuso M, Cotton PB. Endoscopic retrograde cholangiography in hepatic hydatid disease. $\mathrm{Br}$ J Surg 1978;65:107-8.

16. Beggs 1 . The radiology of hydatid disease. Am J Roentgenol 1985;145:639-48.

17. Shemesh E, Friedman E. Radiologic and endoscopic appearances of intrabiliary rupture of hydatid liver disease. Digestion 1987;36:96-100.

18. Munzer D. New perspectives in the diagnosis of Echinococcus disease. J Clin Gastroenterol 1991;13:415-23.

19. Tuttle RJ. Cause of recurring obstructive jaundice revealed by percutaneous cholangiography hydatid cyst. N Engl J Med 1970;283:805-6.

20. Farrelly C, Lawrie BW. Diagnosis of intrabiliary rupture of hydatid cyst of the liver by fine needle percutaneous 
transhepatic cholangiography. $\mathrm{Br}$ ]

Radiol 1982;55:372-3.

21. Mueller PR, Dawson SL, Ferrucci JT, Nardi GL. Hepatic echinoccal cyst: Successful percutaneous drainage. Am J Radiol 1985;155:627-8.

22. Dadoukis J, Gamvros O, Aletras H. Intrabiliary rupture of the hydatid cyst of the liver. World J Surg 1984;8:786-90.

23. Shemesh E, Klein E, Abramowich D, et al. Common bile duct obstruction caused by hydatid daughter cysts.
Management by endoscopic retrograde sphincterotomy. Am J Gastroenterol 1986;81:280-2.

24. Magistrelli P, Masetti R, Coppola R. Value of ERCP in the diagnosis and management of pre and post operative biliary complications in hydatid disease of the liver. Gastrointest Radiol 1989;14:315-20.

25. Al Karawi MA, Mohamed ARE, Yasawy MI, et al. Nonsurgical endoscopic transpapillary treatment of ruptured Echinococcus liver cyst obstructing the biliary tree.

Endoscopy 1987;19:81-3.

26. Iscan M, Duren M. Endoscopic sphincterotomy in the management of post operative complications of hepatic hydatid disease. Endoscopy 1991;23:282-3.

27. Al Karawi MA, Yasawy Mi, El Sheik Mohamed AR. Endoscopic management of biliary hydatid disease. Report on six cases. Endoscopy 1991;23:278-81. 


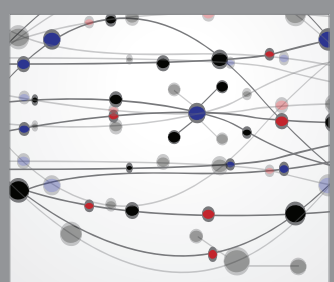

The Scientific World Journal
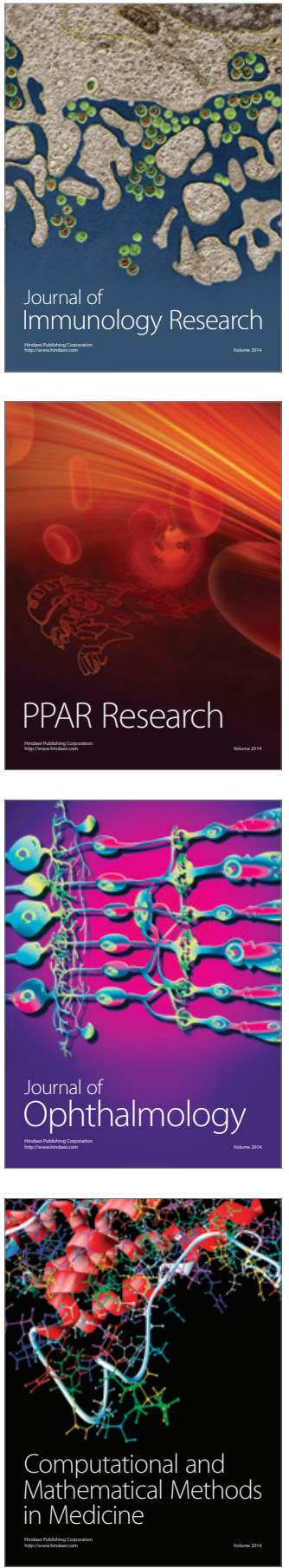

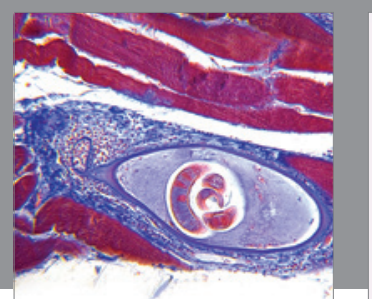

Gastroenterology Research and Practice

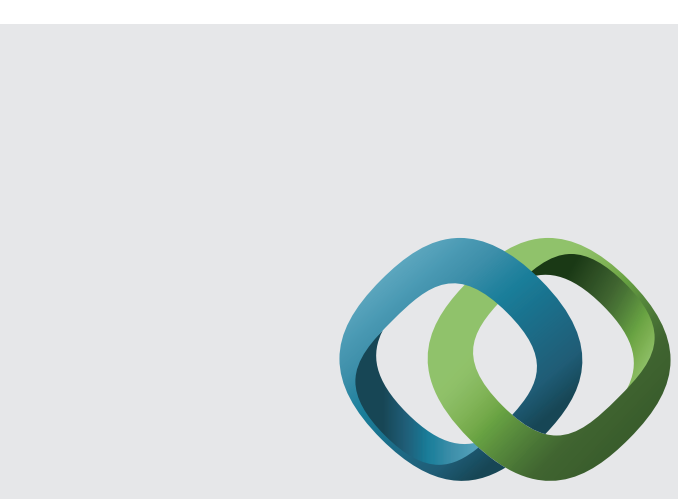

\section{Hindawi}

Submit your manuscripts at

http://www.hindawi.com
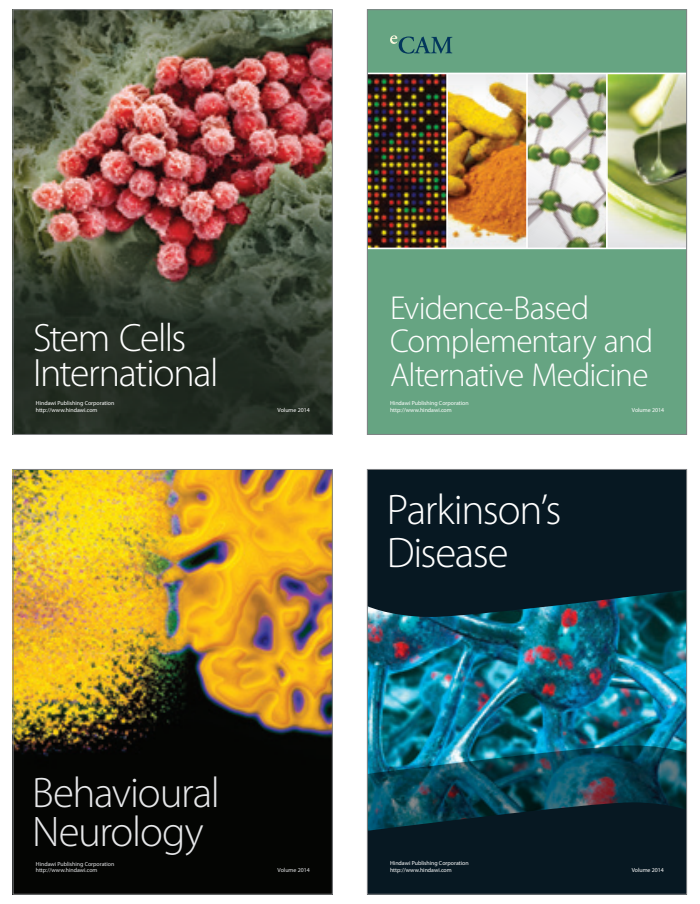
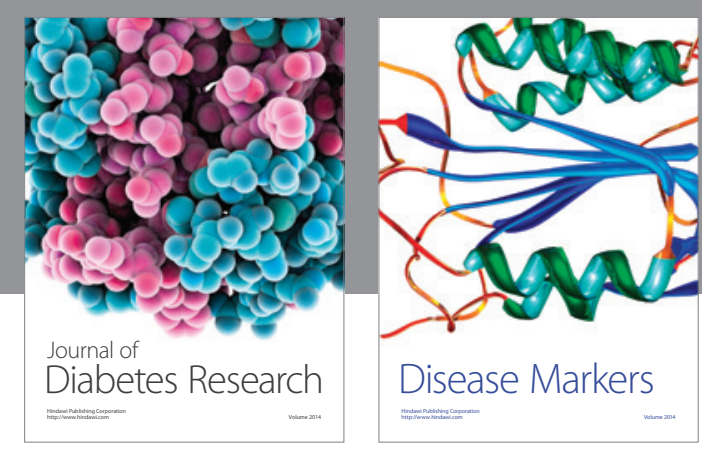

Disease Markers
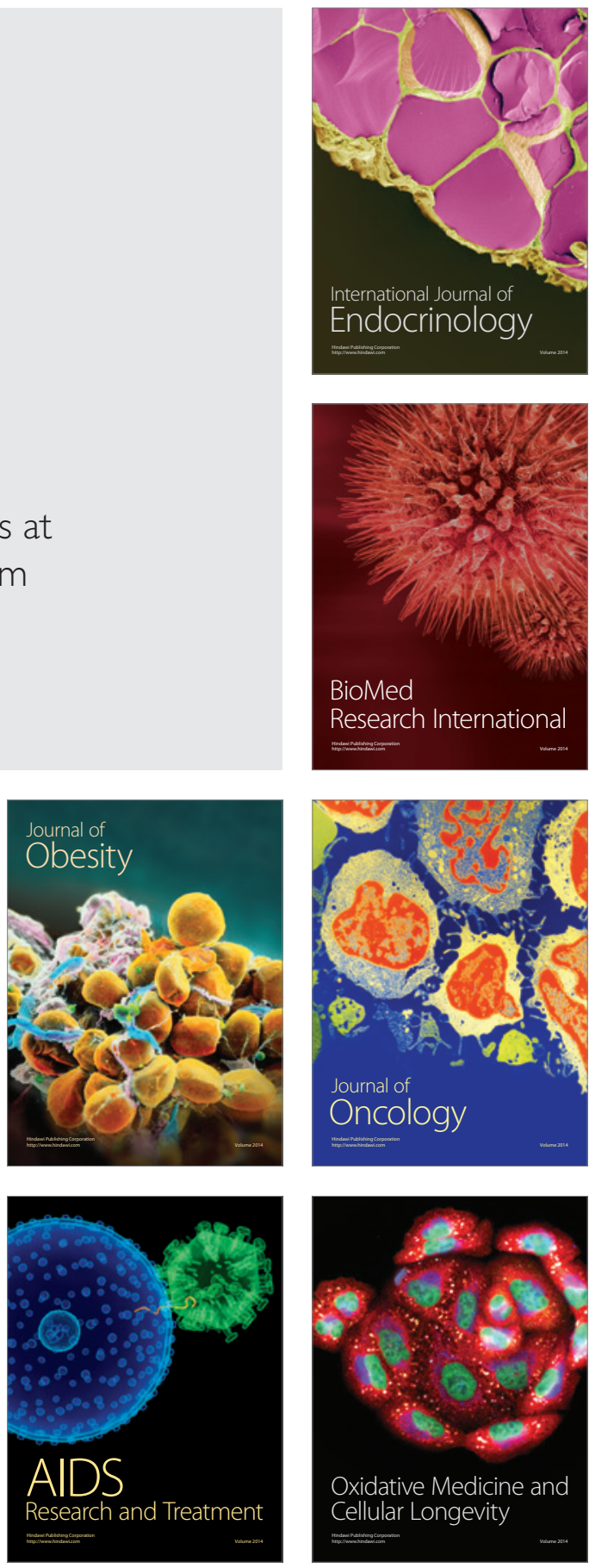